\title{
Involvement of Caspase- 6 and Caspase-8 in Neuronal Apoptosis and the Regenerative Failure of Injured Retinal Ganglion Cells
}

\author{
Philippe P. Monnier, ${ }^{2,3,4 *}$ Philippe M. D’Onofrio, ${ }^{1}$ Mark Magharious, ${ }^{1}$ Adam C. Hollander, ${ }^{1}$ Nardos Tassew, ${ }^{2,4}$ \\ Kinga Szydlowska, ${ }^{4}$ Michael Tymianski, ${ }^{4}$ and Paulo D. Koeberle ${ }^{1 \star}$ \\ ${ }^{1}$ Division of Anatomy, Department of Surgery, ${ }^{2}$ Department of Physiology, and ${ }^{3}$ Department of Ophthalmology, Faculty of Medicine, University of Toronto, \\ Toronto, Ontario M5S 1A8, Canada, and ${ }^{4}$ Toronto Western Research Institute, Toronto, Ontario M5T 2S8, Canada
}

To promote functional recovery after CNS injuries, it is crucial to develop strategies that enhance both neuronal survival and regeneration. Here, we report that caspase-6 is upregulated in injured retinal ganglion cells and that its inhibition promotes both survival and regeneration in these adult CNS neurons. Treatment of rat retinal whole mounts with Z-VEID-FMK, a selective inhibitor of caspase-6, enhanced ganglion cell survival. Moreover, retinal explants treated with this drug extended neurites on myelin. We also show that caspase-6 inhibition resulted in improved ganglion cell survival and robust axonal regeneration following optic nerve injury in adult rats. The effects of Z-VEID-FMK were similar to other caspase inhibitory peptides including Z-LEHD-FMK and Z-VAD-FMK. In searching for downstream effectors for caspase-6, we identified caspase-8, whose expression pattern resembled that of caspase-6 in the injured eye. We then showed that caspase- 8 is activated downstream of caspase- 6 in the injured adult retina. Furthermore, we investigated the role of caspase- 8 in RGC apoptosis and regenerative failure both in vitro and in vivo. We observed that caspase-8 inhibition by Z-IETD-FMK promoted survival and regeneration to an extent similar to that obtained with caspase- 6 inhibition. Our results indicate that caspase- 6 and caspase-8 are components of a cellular pathway that prevents neuronal survival and regeneration in the adult mammalian CNS.

\section{Introduction}

CNS injury results in permanent functional loss due to the inability of adult CNS neurons to regenerate axons, and their susceptibility to apoptosis. Optic nerve transection (axotomy) is a highly reproducible model of apoptosis in adult mammalian CNS neurons (Bähr, 2000; Koeberle and Bähr, 2004), resulting in the degeneration of $90 \%$ of RGCs by $14 \mathrm{~d}$ after axotomy (VillegasPérez et al., 1988; Berkelaar et al., 1994; Quigley et al., 1995). Axonal regeneration in RGCs can also be studied using the optic nerve crush model (Misantone et al., 1984; Barron et al., 1986; Stevenson, 1987; Sautter and Sabel, 1993), in which RGCs regenerate axons through the myelinated optic nerve.

Caspases are a family of cysteine proteases that regulate apoptosis (Baumgartner et al., 2009; Inoue et al., 2009; Yi and Yuan, 2009). Caspases are synthesized as precursors (procaspases) that

\footnotetext{
Received Jan. 10, 2011; revised May 24, 2011; accepted May 30, 2011

Author contributions: P.P.M. and P.D.K. designed research; P.P.M., P.M.D., M.M., A.C.H., N.T., K.S., M.T., and P.D.K. performed research; P.P.M. and P.D.K. analyzed data; P.P.M. and P.D.K. wrote the paper.

This work was supported by Canadian Institutes of Health Research Operating Grant MOP 86523 (P.D.K.).P.P.M. received support from Heart and Stroke Foundation of Ontario Grant NA7067 as well as Canadian Institutes of Health Research Grant MOP 106666. We thank Dr. Freda Miller and Asli Dedeagac for kindly providing the myelin used in our experiments.

*P.P.M. and P.D.K. contributed equally to this work.

Correspondence should be addressed to Paulo D. Koeberle, Division of Anatomy, University of Toronto, MSB 1186, 1 King's College Circle, Toronto, ON M5S 1A8, Canada, E-mail: paulo.koeberle@utoronto.ca; or Philippe P. Monnier, Toronto Western Research Institute, 399 Bathurst Street, MCL 6-412, Toronto, ON M5T 258, Canada, E-mail: pmonnier@uhnres.utoronto.ca.

DOI:10.1523/JNEUROSCI.0148-11.2011

Copyright $\odot 2011$ the authors $\quad 0270-6474 / 11 / 3110494-12 \$ 15.00 / 0$
}

are activated by enzymatic cleavage (Degterev et al., 2003; Inoue et al., 2009). Cleavage of procaspases liberates large $(\sim 20 \mathrm{kDa})$ and small $(\sim 10 \mathrm{kDa})$ subunits that heterodimerize to form catalytically active proteases (Degterev et al., 2003; Guo et al., 2004; Baumgartner et al., 2009). Caspase- 3 and -9 play pivotal roles in the apoptotic death of RGCs after axotomy (Kermer et al., 1998, 1999, 2000; Chaudhary et al., 1999; Weishaupt et al., 2003; Cheung et al., 2004).

The inability of CNS neurons to regenerate is associated with two properties of the mature CNS: non-neuronal growth inhibitory cues and poor intrinsic regenerative ability (Schwab, 1990; Nash et al., 2009; Nishio, 2009; Cao et al., 2010; Sun and He, 2010). The CNS contains several classes of growth-inhibitory cues that prevent the extension of regenerating axons. These include Nogo, MAG, and oligodendrocyte myelin glycoprotein (OMgp) (McKerracher et al., 1994; DeBellard et al., 1996; Li et al., 1996; Fournier et al., 2002; Wong et al., 2003; Cui et al., 2004; Fischer et al., 2004; Su et al., 2008, 2009; Chen et al., 2009), which have been shown to inhibit RGC axon regeneration after injury. Intracellular signaling cascades that are activated by these growth inhibitory cues ultimately converge on Rho-associated kinase (ROCK), thereby inducing growth cone collapse. Accordingly, the ROCK inhibitor $(R)-(+)$-trans-4-(1aminoethyl)-N-(4-pyridyl)cyclohexanecarboxamide dihydrochloride monohydrate (Y-27632) promotes RGC regeneration both in vitro and in vivo (Monnier et al., 2003; Lingor et al., 2007, 2008; Ahmed et al., 2009).

Due to the findings that caspases 3 and 9 were not involved in axonal degeneration (Kuida et al., 1996; Finn et al., 2000), this 

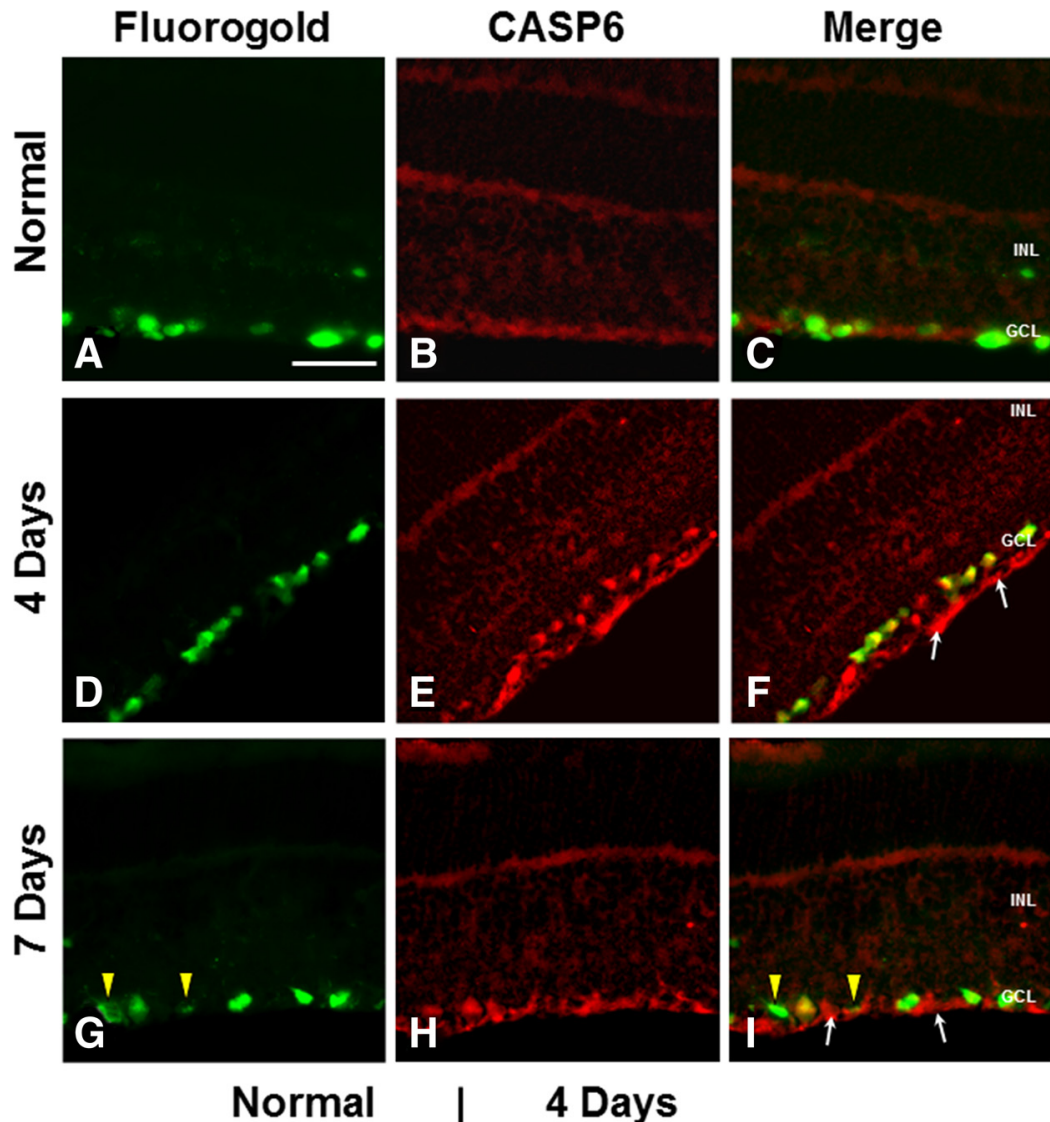

西

4 Days

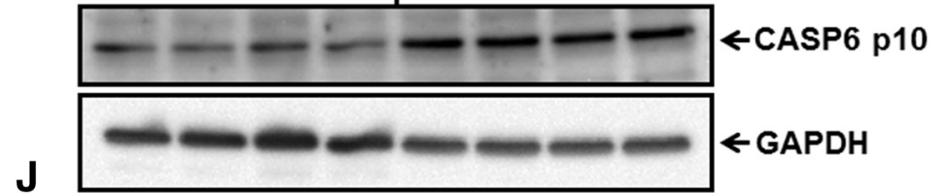

Figure 1. Caspase-6 is upregulated after optic nerve transection. Transverse sections of retinas from normal or optic nerve transected animals were used to study CASP6 expression. Following optic nerve transection, samples were processed at 4 or $7 \mathrm{~d}$ after injury. $\boldsymbol{A}, \boldsymbol{D}, \boldsymbol{G}$, FluoroGold retrograde labeling was performed to identify $\mathrm{RGCs}$ in the ganglion cell layer of the retina. $\boldsymbol{B}, \boldsymbol{E}, \boldsymbol{H}$, Staining with a caspase- 6 antibody for the cleaved active p10 subunit. $\boldsymbol{C}, \boldsymbol{F}, \boldsymbol{I}$, Merge of caspase-6 immunostaining and FluoroGold labeling. In normal retinas, faint caspase-6 staining is seen in the ganglion cell layer $(\boldsymbol{A}-\boldsymbol{C})$. Caspase-6 expression is strongly upregulated 4 and $7 \mathrm{~d}$ following injury $(\boldsymbol{D}-\boldsymbol{I})$. In injured eyes, caspase-6 is observed in the cell bodies of RGCs as well as in the axons of the nerve fiber layer (arrows). At $7 \mathrm{~d}$, additional autofluorescent microglia, which are activated after axotomy, were observed in the ganglion cell layer and nerve fiber layer ( $G$, arrowheads). GCL, Ganglion cell layer; INL, inner nuclear layer. Scale bar, $50 \mu \mathrm{m} . J$, Western blots of whole retinal lysates from normal animals or $4 \mathrm{~d}$ axotomy animals. Axotomized retinas had higher levels of cleaved caspase- 6 p 10 subunit. GADPH loading control is shown below.

process was believed to be caspase independent. However, it has recently been discovered that caspase- 6 is required for neuronal axon degeneration in vitro (Nikolaev et al., 2009). This raises the possibility that caspase- 6 is a critical mediator of the failure of axon regeneration in the adult CNS. Here, we describe a prominent role for caspase- 6 in retinal ganglion cell apoptosis and regenerative failure, both in vitro and in vivo. We also provide evidence that caspase- 8 is a downstream effector of caspase- 6 to regulate both cell survival and axonal regeneration.

\section{Materials and Methods}

Retinal whole-mount cultures. Sprague Dawley rat pups of either sex (P14; Charles River) were anesthetized using $4 \%$ isoflurane and decapitated. After enucleation, eyes were briefly washed in $10 \%$ Germicide and placed in cold medium. Retinas were flat-mounted with the ganglion cell layer (GCL) facing upward on Millicell plate inserts $(0.4 \mu \mathrm{m}$; Millipore). The retinas were cultured for $4 \mathrm{~d}\left(37^{\circ} \mathrm{C}, 5 \% \mathrm{CO}_{2}\right)$ in $1 \mathrm{ml}$ of culture medium, which contained
Neurobasal medium, 10\% fetal bovine serum, $2 \%$ B-27 supplement, $1 \%$ glutamine, $3 \%$ antibiotic/antimycotic (all from Invitrogen), and Z-VEID-FMK (caspase-6 inhibitor; R\&D Systems), Z-IETD-FMK (caspase-8 inhibitor; R\&D Systems), or DMSO (control).

To assess cell survival, propidium iodide (PI) (final concentration, $2 \mu \mathrm{g} / \mathrm{ml}$ ) was added directly to the medium and images were taken at the same intensity using a fluorescence microscope every $24 \mathrm{~h}$. Images of PI-stained retinas were analyzed using ImageJ, and the fluorescence intensity at each time point was quantified, and background fluorescence was subtracted.

Retinal-explant cultures. Glass coverslips were treated with $10 \mu \mathrm{g} / \mathrm{ml}$ poly-L-lysine, washed, and dried. The coverslips were further treated with laminin $(10 \mu \mathrm{g} / \mathrm{ml})$, and myelin preparations (kind gift from Dr. Freda Miller) were added and centrifuged for $15 \mathrm{~min}$ at $3000 \times g$ and $4^{\circ} \mathrm{C}$. Alternatively, 10, 5, or 3 $\mu \mathrm{g} / \mathrm{ml}$ chondroitin sulfate proteoglycan (CSPG) mixture (Millipore Bioscience Research Reagents) mixed with laminin $(10 \mu \mathrm{g} /$ $\mathrm{ml}$; Sigma-Aldrich) was added to the coverslips in a sandwich format and incubated for $2 \mathrm{~h}$ at room temperature. Explants from E7 chick retinas were then prepared as we published previously (Monnier et al., 2003), added to either the membrane- or protein-coated surfaces in DMEM/F-12 media (2\% chick serum, 10\% FBS), and placed in an incubator $\left(37^{\circ} \mathrm{C}, 5 \%\right.$ $\mathrm{CO}_{2}$ ) for $18 \mathrm{~h}$, in the presence of either caspase inhibitory peptides $(10 \mu \mathrm{M})$, ROCK inhibitor (Y-27632; $50 \mu \mathrm{M})$, or DMSO $(10 \mu \mathrm{l} / \mathrm{ml}$; control). The explants were then fixed in 4\% PFA, permeabilized with $0.1 \%$ Triton X-100 in PBS, stained with Alexa 488-Fluor-phalloidin and viewed under a fluorescence microscope (Zeiss). The number and length of fibers were then quantified using ImagePro 5.0. Only explants which displayed outgrowth were considered for the quantification.

Optic nerve transection and optic nerve crush. Adult female Sprague Dawley rats free of common pathogens were used in all experiments. Animals were kept in a pathogen-controlled environment and housed in standard cages equipped with micron air filters. Animals were cared for according to the Canadian Council on Animal Care.

Animals were placed in a stereotaxic frame and anesthetized with isoflurane $(2 \% ; 0.8 \mathrm{~L} / \mathrm{min}$ oxygen flow rate) delivered through a gas anesthesia mask. Lidocaine eye drops were used to anesthetize the cornea, and ophthalmic eye ointment was applied to the cornea to prevent desiccation during surgery. The optic nerve was accessed within the ocular orbit via an incision in the tissue covering the superior border of the orbital bone. The superior orbital contents were dissected and the rectus muscles reflected laterally. To allow access to the optic nerve and surrounding dura mater sheath, the eye was rotated laterally by applying traction to the extraocular muscles. The dural sheath surrounding the optic nerve was cut longitudinally, to avoid damaging blood vessels supplying the retina. The optic nerve was gently lifted from the meningeal sheath and transected within $2 \mathrm{~mm}$ of the back of the eye. To retrogradely label RGCs, Gelfoam soaked in 2\% FluoroGold (Sigma-Aldrich) was placed over the transected optic nerve stump. The optic nerve crush procedure was performed using a similar approach; however, the optic nerve was crushed using fine self-closing forceps for $6 \mathrm{~s}$. The orbital contents were 
returned to their original location and the initial incision was closed. Following surgery, rats were placed in a recovery cage under a heat lamp and given ketoprofen to ease postsurgical recovery.

Intraocular injections. Animals received intraocular injections of five different caspase inhibitors: the pancaspase inhibitor Z-VADFMK, the caspase-9 inhibitor Z-LEHD-FMK, the caspase- 8 inhibitor Z-IETD-FMK, the caspase-6 inhibitor Z-VEID-FMK, or a chemically synthesized caspase-6 inhibitor [sulfonamide isatin Michael acceptor (SIMA 13a) (Chu et al., 2009)]. Peptide caspase inhibitors were purchased from R\&D Systems, and SIMA 13a was synthesized by Toronto Research Chemicals. Inhibitors were dissolved in sterile DMSO.

Intraocular injections of experimental or control vehicle solutions were administered at $3 \mathrm{~d}$ after axotomy, before the onset of RGC apoptosis, which occurs at $4-5 \mathrm{~d}$ after axotomy. For the study of axon regeneration, intraocular injections were delivered at 3 and $10 \mathrm{~d}$ after optic nerve crush. Animals were placed in a stereotaxic frame and anesthetized with isoflurane, delivered through a gas anesthetic mask. The cornea was anesthetized using Alcaine eye drops (Alcon) before intraocular injections. A pulled glass micropipette attached to a $10 \mu$ l Hamilton syringe via a hydraulic coupling through PEEK tubing was used to deliver $4 \mu \mathrm{l}$ of a solution into the vitreous chamber of the eye, posterior to the limbus. Care was taken to prevent damage to the lens or anterior structures of the eye that have been shown to secrete confounding growth factors. The pipette was held in place for $5 \mathrm{~s}$ after injection and slowly withdrawn from the eye to prevent reflux. Injections were performed using a surgical microscope to visualize pipette entry into the vitreous chamber and confirm delivery of the injected solution.

Quantification of RGC survival after injury. Eyes were enucleated, the cornea and lens were removed, and the remaining eye cups containing the retinas were fixed in $4 \%$ paraformaldehyde at $14 \mathrm{~d}$ after axotomy. Eye cups were fixed for $1 \mathrm{~h}$ and then rinsed in PBS for $15 \mathrm{~min}$. The retinas were then extracted, flat-mounted, and coverslipped using 50:50 glycerol/PBS. FluoroGold staining in RGCs was visualized using an Andor iXon 885+ EMCCD camera attached to a Leica DM LFSA microscope. The illumination source was a Sutter Lambda XL with a liquid light guide ensuring even field illumination. RGC densities were sampled at the inner ( $1 / 6$ retinal eccentricity), midperiphery (1/2 retinal eccentricity), or outer retina (5/6 retinal eccentricity) of each quadrant of the flat mount. RGC densities were grouped by retinal eccentricity (inner, middle, outer) and expressed as mean \pm SEM. ANOVA followed by post hoc analysis using Tukey's post hoc comparisons $(p<$ 0.01 ) were used to determine statistical significance between experimental and control samples.

Quantification of $R G C$ regeneration and GAP-43 immunohistochemistry. RGC axon regeneration was examined at $21 \mathrm{~d}$ after optic nerve crush. Two days before removal of the nerve and fixation, the anterograde tracer FITC-conjugated cholera toxin B (CTB-FITC) was injected into the vitreous chamber of the eye to anterogradely trace axons that are intact and
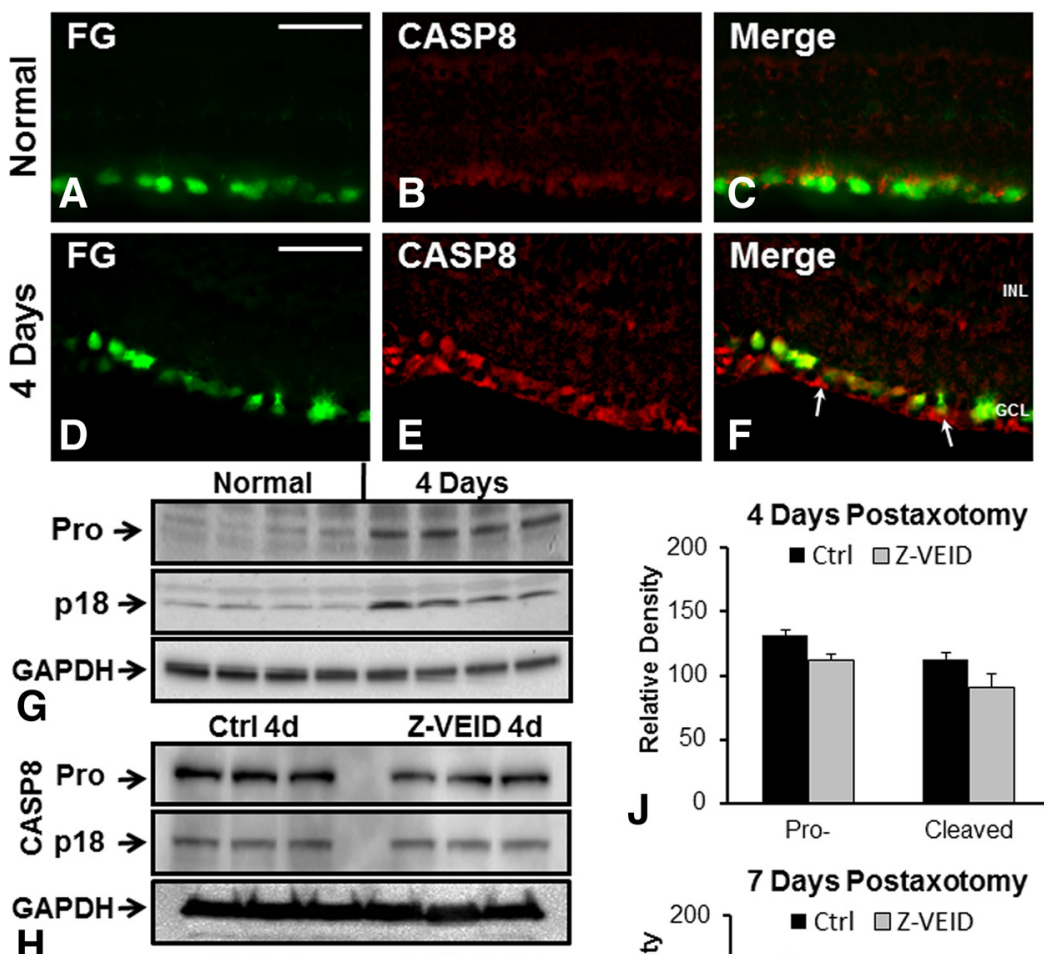

4 Days Postaxotomy

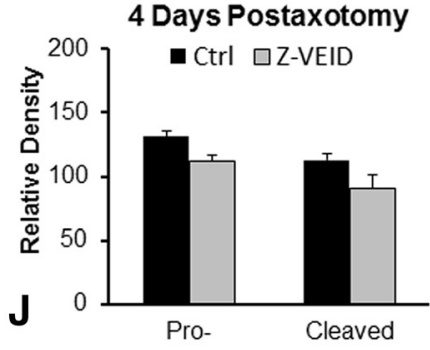

7 Days Postaxotomy
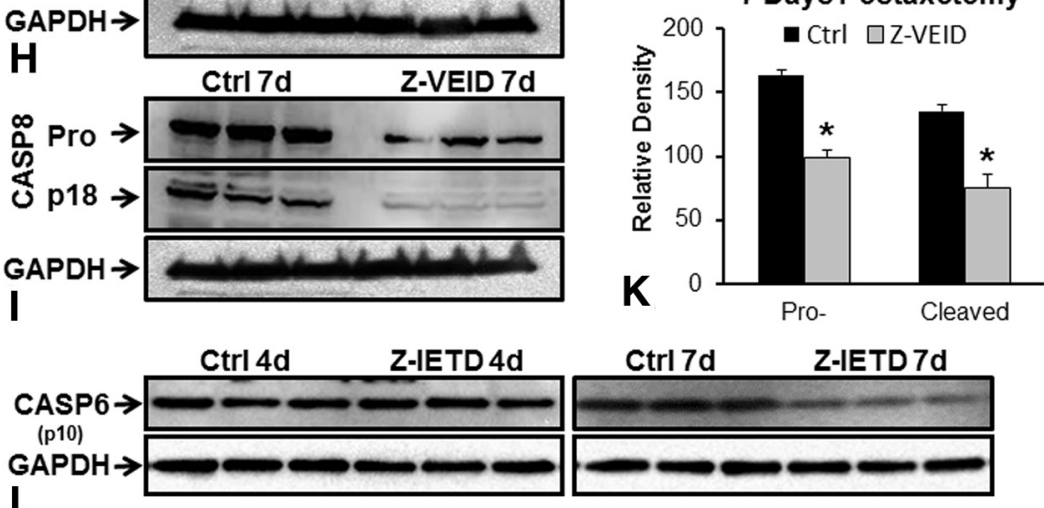

Figure 2. Caspase-6-dependent upregulation of caspase-8. Transverse sections of normal $(\boldsymbol{A}-\boldsymbol{C})$ or $4 \mathrm{~d}$ axotomy $(\boldsymbol{D}-\boldsymbol{F})$ retinas were used to study CASP8 localization. $\boldsymbol{A}, \boldsymbol{D}$, FluoroGold retrograde labeling in RGC somata. $\boldsymbol{B}, \boldsymbol{E}$, Caspase-8 (p18 cleaved subunit) staining indicates that caspase-8 is expressed in RGC cell bodies and their axons in the nerve fiber layer $(\boldsymbol{I}$, arrows) at $4 \mathrm{~d}$ after axotomy $(\boldsymbol{E})$, whereas only weak staining was observed in normal retinas $(\boldsymbol{B})$. $\boldsymbol{C}, \boldsymbol{F}$, Merge of two corresponding images on the left. GCL, Ganglion cell layer; $I N L$, inner nuclear layer. Scale bar, $50 \mu \mathrm{m}$. G, Western blot analysis of normal and $4 \mathrm{~d}$ axotomy retinas, directed at both procaspase-8 and the cleaved p18 caspase-8 subunit. Two bands of 54 and 18 kDa corresponding to procaspase- 8 (Pro) and active caspase-8 (p18) are shown, with the corresponding GAPDH loading control below. $\boldsymbol{H}_{\boldsymbol{I}} \boldsymbol{I}$, The optic nerve was transected and animals received intraocular injections of MSO (control) or a caspase-6 inhibitor (Z-VEID). At $4 \mathrm{~d}(\boldsymbol{H})$ or $7 \mathrm{~d}(\boldsymbol{I})$ after axotomy, caspase-8Western blots were performed. Correspondaxotomy $(\boldsymbol{J})$ or $7 \mathrm{~d}$ after axotomy $(\boldsymbol{K})$. The intensity of the bands was measured relative to the amount of GAPDH in each sample. Results are expressed as the mean of three separate retinas \pm SEM. Z-VEID injection significantly reduced the amount of procaspase- 8 and active caspase- $8 \mathrm{p} 18$ at $7 \mathrm{~d}$ following injury $(\boldsymbol{K}) .{ }^{*} p<0.01$. L, Western blots directed against the cleaved caspase- 6 p10 subunit in normalunlesioned retinas or axotomized retinas at 4 or 7 dafter injury and caspase-8 inhibition (Z-IETD-FMK) or control treatment (vehicle). GAPDH loading controls are shown below.

demonstrating protein transport within the retina. At $21 \mathrm{~d}$, animals received intracardial perfusions of $4 \%$ paraformaldehyde, and the optic nerves were removed. Nerves were postfixed in $4 \%$ paraformaldehyde overnight at $4^{\circ} \mathrm{C}$, and then rinsed in PBS. The fixed nerves were cryoprotected in 30\% sucrose in PBS for $7 \mathrm{~d}$ and then sectioned using a Leica CM1950 cryostat microtome. Transverse sections of optic nerve were collected on APTEX (Sigma-Aldrich)-coated slides and stored at $-20^{\circ} \mathrm{C}$ until immunostaining was performed.

Immunohistochemistry was performed on transverse frozen sections of optic nerves. Sections were incubated overnight at $4^{\circ} \mathrm{C}$ in primary antisera directed against growth-associated protein-43 (GAP-43), an axon marker in regenerating adult retinal ganglion cells (Meyer et al., 

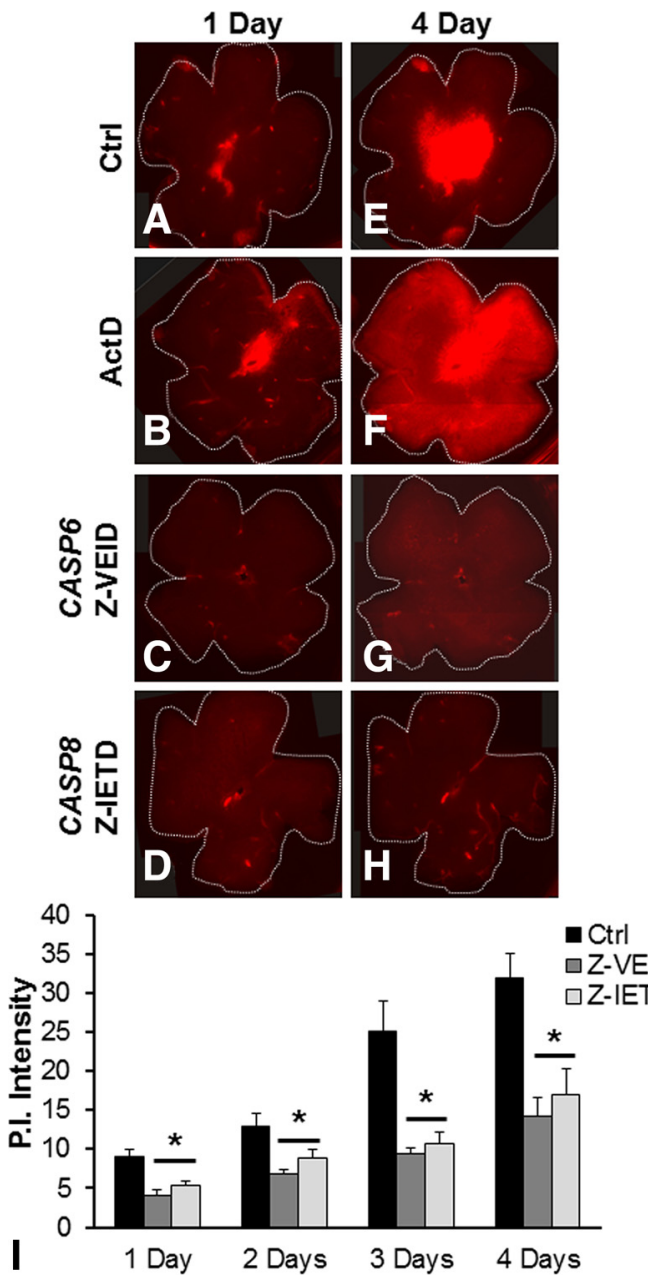

Figure 3. Inhibition of caspase-6 or caspase-8 promotes cell survival in retinal whole mounts. Retinal whole mounts were prepared and incubated with either DMSO (control), actinomycin D (positive control), caspase-6 inhibitor (Z-VEID-FMK), or caspase-8 inhibitor (Z-IETDFMK). Dead cells were stained with PI following $1 \mathrm{~d}(\boldsymbol{A}-\boldsymbol{D})$ or $4 \mathrm{~d}(\boldsymbol{E}-\boldsymbol{H})$ incubation. After $4 \mathrm{~d}$, the presence of either Z-VEID or Z-IETD in the medium strongly reduced the number of PI-positive cells. I, Quantification of the PI intensity over a $4 \mathrm{~d}$ period. Pictures from 27 whole mounts $(9$ for each condition) from three independent experiments were taken at equal intensities and the fluorescence measured using ImageJ. At all time points, the intensity of PI staining in retinal whole mounts incubated with either caspase- 6 or caspase- 8 inhibitors was significantly reduced when compared with control $\left({ }^{*} p<0.01\right)$. Error bars indicate SEM.

1994; Berry et al., 1996; Leon et al., 2000; Su and Cho, 2003; Su et al., 2008, 2009). Primary antisera were diluted in PBS containing 0.3\% Triton X-100 and 3\% normal serum. Following primary antibody incubation, sections were rinsed three times for $15 \mathrm{~min}$ in PBS and incubated with FITC-labeled secondary antibody for $3 \mathrm{~h}$ at room temperature. Sections were then rinsed three times for 15 min each time in PBS and coverslipped with 50:50 glycerol/PBS.

Axon regeneration following optic nerve crush was quantified in longitudinal frozen sections ( $14 \mu \mathrm{m}$ thick) of optic nerve, following GAP-43 immunohistochemistry. The total number of regenerating axon growth cones within bins of the optic nerve, starting at the crush site and proceeding distally, were quantified. The bins were as follows: 0-250, 250500 , and $>500 \mu \mathrm{m}$. A total of four equally spaced sections through the width of each optic nerve were examined and quantified using a Leica DM LFSA microscope $(20 \times$ objective) with an Andor iXon $885+$ camera, with EM gain applied. The total number of regenerating axons per section in each bin was then averaged and statistical analysis was performed by ANOVA, and Tukey's post hoc comparisons at $p<0.01$.

Western blots. Western blots on whole retinas were performed as previously described (Koeberle and Bähr, 2008). Animals were killed at 4 or
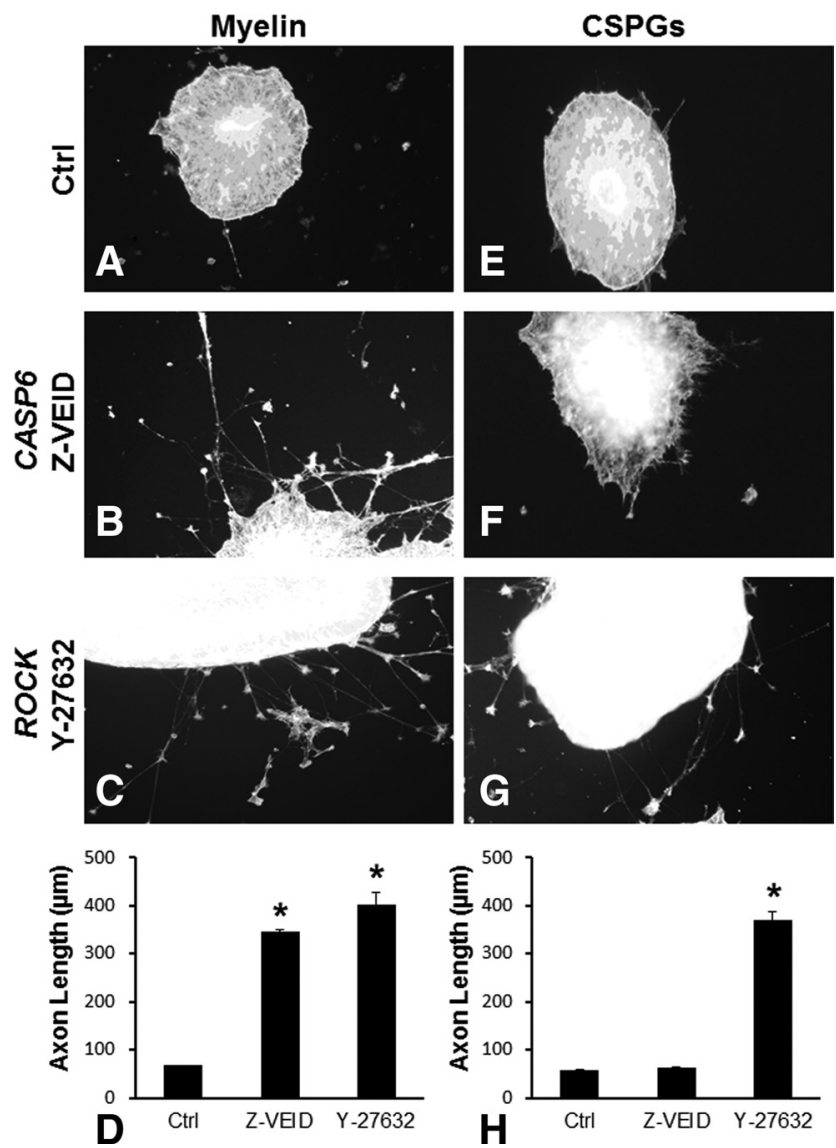

Figure 4. Caspase-6 inhibition promotes axonal outgrowth on myelin but not on CSPGs $A-D$, Retinal explants were cultured on myelin plus DMSO (control; $A$ ), myelin plus caspase-6 inhibitor (Z-VEID; $\boldsymbol{B}$ ), or myelin plus Rho-kinase inhibitor (Y-27632; C). D, Quantification of four independent experiments shows that the presence of either Z-VEID or Y-27632 significantly promotes outgrowth on myelin when compared with control. $\boldsymbol{E}-\boldsymbol{H}$, Retinal explants were cultured on CSPGs plus DMSO (control; E), CSPGs plus caspase-6 inhibitor (Z-VEID; $\boldsymbol{F}$ ), or CSPGs plus Rho-kinase inhibitor (Y-27632; G). $\boldsymbol{H}$, Quantification of four independent experiments shows that the presence of $\mathrm{Y}$-27632 but not Z-VEID significantly promotes outgrowth on CSPGs when compared with controls. ${ }^{*} p<0.01$. Error bars indicate SEM.

$7 \mathrm{~d}$ following intraocular injection of Z-VEID-FMK, Z-IETD-FMK, or a control vehicle injection. Retinas were quickly extracted in ice-cold PBS. Each retina was placed in $300 \mu \mathrm{l}$ of ice-cold SDS lysis buffer (2\% SDS, $0.3 \%$ DTT, $10 \%$ glycerol in $40 \mathrm{~mm}$ Tris-Cl, $\mathrm{pH} 6.8$ ). The retinas were then sonicated and the remaining solutions were heated to $90^{\circ} \mathrm{C}$ for $8 \mathrm{~min}$, centrifuged $\left(12,000 \mathrm{rpm}, 10 \mathrm{~min}, 4^{\circ} \mathrm{C}\right)$, and the protein samples were separated from the pelleted debris. Protein samples were then stored at $-80^{\circ} \mathrm{C}$ for future use. Total protein fractions were separated by SDSPAGE on Bio-Rad TGX Gels (10\% acrylamide) and immunoblotted after semidry electrotransfer to nitrocellulose membranes ( $0.2 \mu \mathrm{m}$ pore size). All blots were blocked in 5\% milk in Tris-buffered saline containing $0.1 \%$ Tween 20 (TBS-T) for $1 \mathrm{~h}$ at room temperature. Blots were then incubated overnight at $4^{\circ} \mathrm{C}$, with gentle shaking. The primary antibody (1: 500; rabbit-anti-caspase-8 (CASP8) p18; Santa Cruz Biotechnology; or 1:500; rabbit-anti-caspase-6 (CASP6) p10; Santa Cruz Biotechnology) was dissolved in $1 \%$ milk in TBS-T. Following primary antibody incubation, blots were washed three times for 15 min each time in TBS-T and incubated in a 1:2000 dilution of secondary antibody (horseradish peroxidase conjugated, cross-reacted against rat serum antigens; Jackson ImmunoResearch) dissolved in 5\% milk in TBS-T. Afterward, the membranes were rinsed three times for $15 \mathrm{~min}$ each time in TBS-T and visualized. Chemiluminescent immunoreactive complexes were visualized using a Bio-Rad Fluor-S Max imager. Loading was verified by reprobing blots with antisera directed against GAPDH (1:1000; rabbit polyclonal; Cell Signaling Technology). For quantification, densitometry was per- 
formed. The density of each band was normalized against the density of the corresponding GAPDH band for each lane. Normalized densitometry values for each experimental group were then averaged \pm SEM, and statistically significant differences between experimental and control groups were calculated using a Welch-corrected, unpaired $t$ test.

\section{Results}

Caspase- 6 activates caspase- 8 in injured retinal ganglion cells

To determine whether caspase- 6 is involved in apoptosis after optic nerve transection, we assessed its expression before and after injury. To localize ganglion cells within the retina, we injected FluoroGold into the superior colliculus at $7 \mathrm{~d}$ before axotomy, thereby retrogradely labeling RGCs (Fig. $1 A)$. Optic nerve transection induced strong caspase- 6 activation both in the cell bodies and axons of retinal ganglion cells (Fig. 1). Caspase-6 activation was apparent over an extended time window, as strong immunoreactivity was observed between $4 \mathrm{~d}$ (Fig. $1 D-F$ ) and $7 \mathrm{~d}$ (Fig. $1 G-I$ ) following axotomy. At $7 \mathrm{~d}$, additional fluorescence was observed in the ganglion cell layer and nerve fiber layer, corresponding to autofluorescence in activated retinal microglia (Fig. 1G-I). Western blotting analysis confirmed the increase in cleaved caspase- 6 p 10 subunit in retinal lysates at $4 \mathrm{~d}$ after axotomy (Fig. $1 J$ ). During Wallerian degeneration, the downstream targets of caspase- 6 are unknown, despite a clear role for BAX upstream of caspase-6 (Nikolaev et al., 2009). We sought to identify a downstream effector of caspase-6. To do so, we used antibodies directed against possible caspase- 6 targets and searched for proteins that are activated both in the soma and axons of RGCs after optic nerve transection. An antibody directed against the activated caspase- 8 p 18 subunit displayed a similar localization to that of caspase- 6 at $4 \mathrm{~d}$ after axotomy (Fig. $2 D-F)$, whereas only weak staining was observed in normal retinas (Fig. $2 A-C$ ). Increased levels of procaspase- 8 and active caspase- 8 (p18), relative to normal-unlesioned retinas, were also observed in axotomized retinas at $4 \mathrm{~d}$ after axotomy (Fig. $2 G$ ). To test whether caspase- 6 regulates caspase- 8 activity, we delivered intraocular injections of the caspase- 6 inhibitor Z-VEID-FMK (at $3 \mathrm{~d}$ ) and examined procaspase- 8 cleavage in Western blots at 4 or $7 \mathrm{~d}$ after axotomy (Fig. $2 \mathrm{H}, I$ ). Z-VEID-FMK treatment did not significantly alter procaspase- 8 or cleaved caspase- 8 (p18) levels at $4 \mathrm{~d}$ after axotomy (Fig. $2 J$ ). Of note, the levels of procaspase- 8 and cleaved-active caspase- 8 (p18) at $7 \mathrm{~d}$ after axotomy were significantly reduced by caspase-6 inhibition (Fig. $2 I, K$ ), indicating that caspase- 6 is upstream of caspase- 8 .

To determine whether caspase- 6 activation is dependent on caspase- 8 activity, we examined procaspase- 6 cleavage following intraocular injection of Z-IETD-FMK at 4 and $7 \mathrm{~d}$ after axotomy
CASP8: Z-IETD

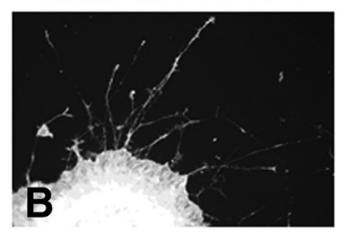

ROCK: Y-27632
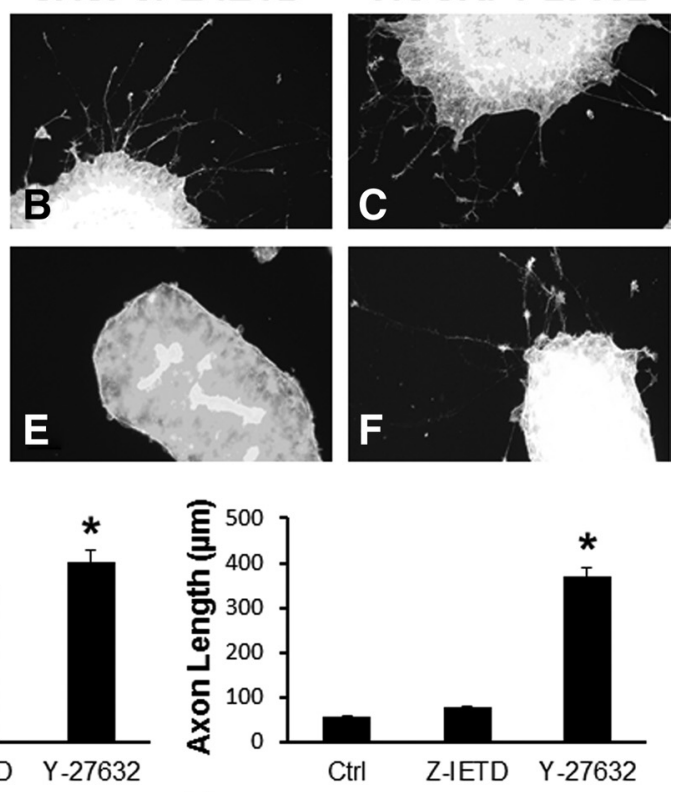

H

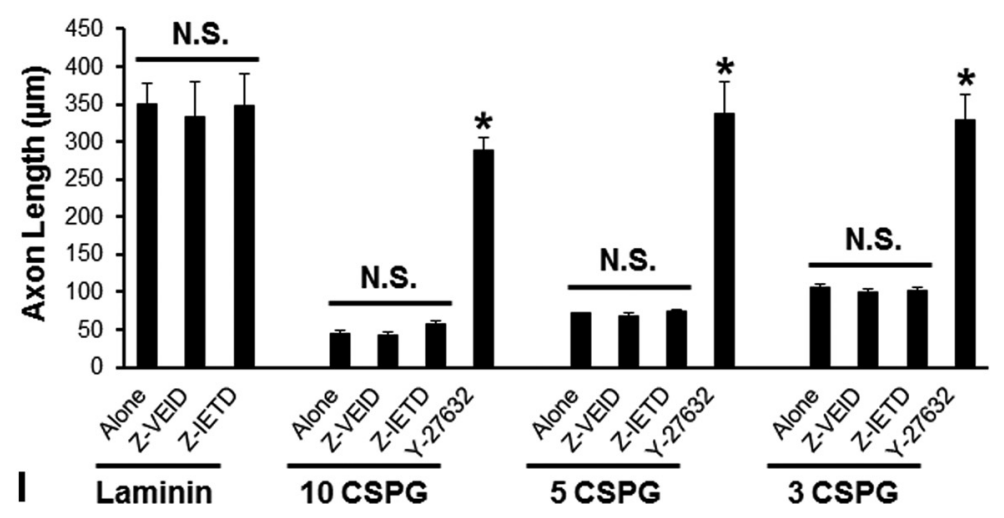

Figure 5. Caspase-8 inhibition promotes axonal growth on myelin but not on CSPGs. A-C, Retinal explants were cultured on myelin plus DMSO (control; $\boldsymbol{A}$ ), myelin plus caspase-8 inhibitor (Z-IETD; $\boldsymbol{B}$ ), or myelin plus Rho-kinase inhibitor (Y-27632; $\boldsymbol{C}$. D - $\boldsymbol{F}$ 列 ( 列 concentrations of CSPGs, there was no significant difference between control, Z-VEID, or Z-IETD treatments, whereas Y-27632 induced significant outgrowth. ${ }^{*} p<0.01$. Error bars indicate SEM.

(Fig. $2 \mathrm{~L}$ ). At $4 \mathrm{~d}$ after axotomy, Z-IETD-FMK did not affect the cleavage of procaspase- 6 , as indicated by similar levels of the active CASP6 p10 subunit following Z-IETD or control vehicle injection (Fig. $2 L$ ). There was a small reduction in CASP6 p10 subunit levels at $7 \mathrm{~d}$ after axotomy in Z-IETD-FMK-treated retinas (Fig. $2 L$ ); however, this effect was far less prominent that that observed on procaspase- 8 cleavage in the presence of a caspase- 6 inhibitor (Fig. 2I). Together, these data indicate that caspase- 8 is an important downstream target of caspase- 6 in injured RGCs.

Inhibition of caspase- 6 and -8 promotes retinal ganglion cell survival in organotypic culture

To ascertain whether caspase- 6 is involved in RGC death, we examined RGC survival in retinal whole mounts. When the retina is excised, the severing of RGC axons deprives them of trophic 

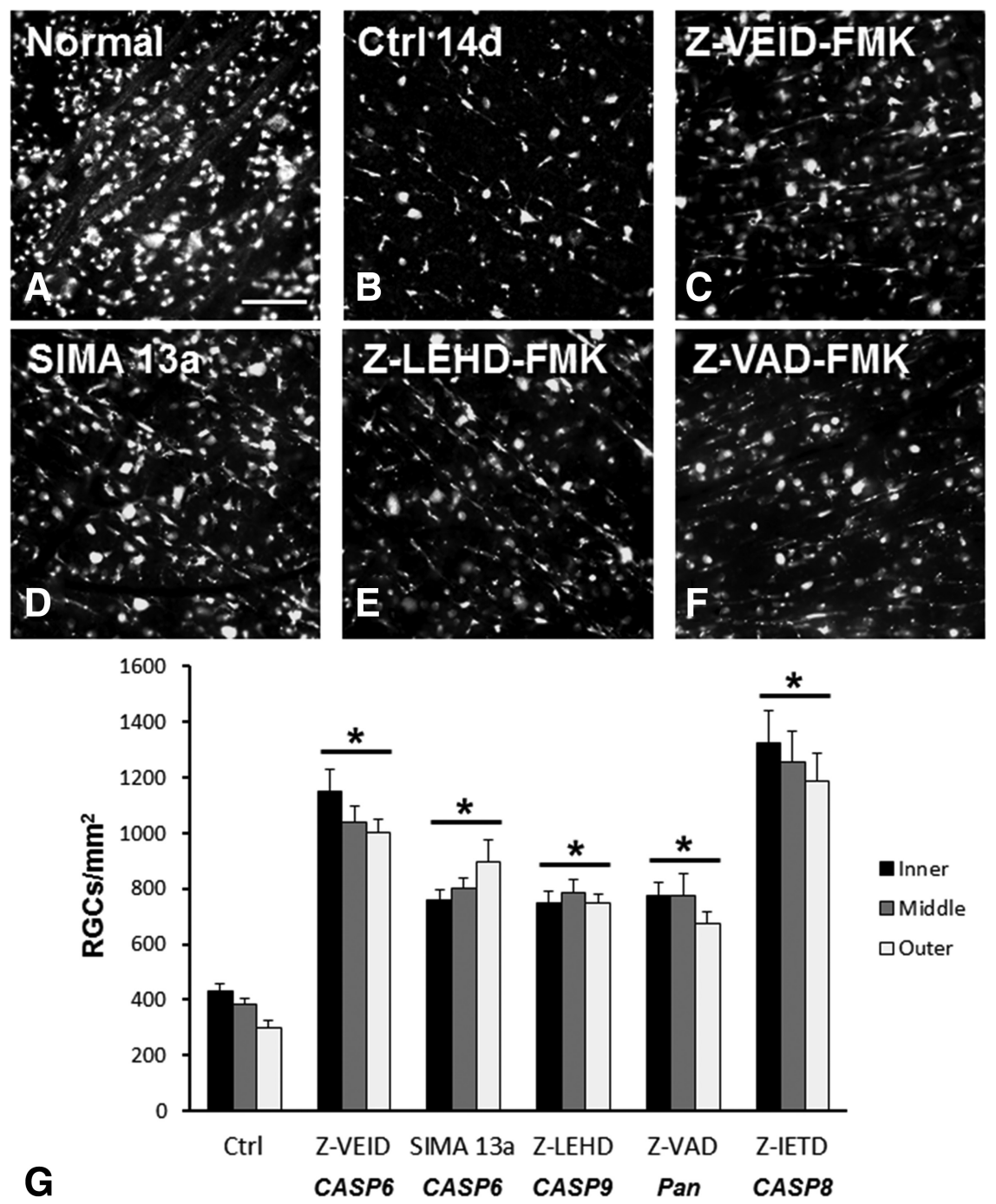

Figure 6. Caspase inhibition promotes cell survival after optic nerve transection. $\boldsymbol{A}-\boldsymbol{F}$, Fluorescence micrographs of flatmounted retinas depicting FluoroGold-labeled RGCs in normal $(\boldsymbol{A})$ or injured retinas at $14 \mathrm{~d}$ following axotomy and various treatments $(\boldsymbol{B}-\boldsymbol{F})$. $\boldsymbol{B}$, Control retinas at $14 \mathrm{~d}$ after axotomy had few surviving RGCs interspersed between transcellularly labeled microglia. Caspase-6 inhibition (C, Z-VEID-FMK; D, SIMA 13a) increased RGC survival after axotomy, to an extent similar to caspase-9 inhibition (E; Z-LEHD-FMK) or pancaspase inhibition ( $\boldsymbol{F}$; Z-VAD-FMK). G, Quantification of the density of surviving RGCS ( \pm SEM) at $14 \mathrm{~d}$ following axotomy and treatment with caspase inhibitors. Z-VEID, SIMA13a, Z-LEHD, Z-VAD, or Z-IETD (caspase-8 inhibitor) significantly increased RGC survival ( $p<0.01$ ) at $14 \mathrm{~d}$ after axotomy. Scale bar, $50 \mu \mathrm{m}$.

factors, thereby inducing apoptosis (Koeberle et al., 2010). Thus, organotypic retinal cultures are a useful in vitro model of RGC axotomy induced death. PI was used to label the nuclei of dead cells in these organotypic cultures. Control retinas showed noticeable PI staining within the first day of culture (Fig. $3 A, E$ ). More prominent PI staining was observed at $4 \mathrm{~d}$ in culture, near the optic disc, where RGC axons exit the retina. As a further control, we added actinomycin D to the medium, which hampers protein synthesis, thereby inducing cell death. Actinomycin D resulted in widespread PI staining throughout the retina by $4 \mathrm{~d}$ in culture (Fig. $3 B, F$ ). Cell death was reduced by the addition of either caspase-6 (Fig. $3 C, G$ ) or caspase-8 (Fig. $3 D, H$ ) inhibitors to the culture medium. A significant difference between control and $10 \mu \mathrm{M}$ Z-VEID-treated retinas appeared after $1 \mathrm{~d}$ in culture and was maximal after $4 \mathrm{~d}$ in culture, with a staining intensity 2.2 times lower following Z-VEID delivery (14.26 \pm 2.42$)$, when compared with controls $(31.99 \pm 2.99)$ (Fig. 3I). Inhibition of caspase-8, with $10 \mu \mathrm{M}$ Z-IETD, showed similar cell preservation with a corresponding twofold decrease in PI intensity (from $31.99 \pm 2.99$ to $16.96 \pm$ 3.29) after $4 \mathrm{~d}$ (Fig. 3I). Thus, caspase-6 and caspase- 8 inhibitors displayed similar rescue efficiencies on PI-labeled cells, which fits with the hypothesis that they may be involved in the same cascade of events.

Caspase-6/8 inhibition promotes axon outgrowth on myelin but not on CSPGs To test the role of caspases 6 and 8 on axonal outgrowth inhibition, we cultured retinal explants on laminin substrates containing either myelin or CSPG. Because the Rho kinase inhibitor Y-27632 is known to suppress both myelin and CSPG inhibition (Fournier et al., 2003; Monnier et al., 2003), Y-27632 was used as a positive control for comparative purposes. Axonal outgrowth is typically abortive when a growing axon encounters inhibitory substrates (Horner and Gage, 2000), and as expected, outgrowth on either myelin or CSPGs was very poor (Fig. 4A,E). In four independent experiments, axonal growth on myelin was significantly enhanced when the caspase- 6 inhibitor Z-VEID-FMK was added to the medium (Fig. 4B). Caspase-6 inhibition increased average axonal length 5.1 times, from $67.7 \pm 0.3$ to $345.2 \pm 4.8 \mu \mathrm{m}$ (Fig. $4 D$ ). In comparison, Y-27632 (Fig. 4C) increased neurite outgrowth by 5.9 times, from $67.7 \pm 0.3$ to $402 \pm 27.1 \mu \mathrm{m}$ (Fig. $4 D$ ). Interestingly, caspase-6 inhibition did not promote outgrowth on CSPGs (Fig. $4 F, H)$. However, under similar conditions, Y-27632 overcame the CSPGmediated inhibition of axon outgrowth (Fig. 4G,H) with a 6.3-fold increase in average axon length $(369.7 \pm 18.7 \mu \mathrm{m})$.

On myelin, caspase- 8 inhibition (Fig. $5 B, G)$ improved outgrowth by 5.2 times (67.7 \pm 0.3 to $349.5 \pm 11.3 \mu \mathrm{m})$, an extent comparable with that observed with either caspase-6 (Fig. 4) or Rho kinase inhibition (Fig. 5C,G). Moreover, similar to caspase-6, caspase-8 inhibition did not affect axonal growth on CSPGs (77.6 \pm $3.2 \mu \mathrm{m}$ ) (Fig. $5 E, H$ ). The findings that caspase- 6 or -8 inhibition did not restore outgrowth on CSPGs suggest that these treatments specifically neutralize the effects of myelin inhibition. To further address this issue, we tested outgrowth on the permissive substrate, laminin. Neurite outgrowth on laminin was not altered by Z-VEID or Z-IETD (Fig. 5I), indicating that the enhanced outgrowth observed on myelin was a result of alleviating inhibition rather than a nonspecific promotion of axon outgrowth. Additionally, we tested lower concentrations of CSPGs to determine whether the lack of outgrowth on CSPGs after Z-VEID or Z-IETD treatment was due to saturating CSPG concentrations. The mean axon length on a CSPG substrate increased by approximately twofold when the concentration of CSPGs was reduced from 10 to $3 \mu \mathrm{g} / \mathrm{ml}$ (Fig. 5I). However, for any given CSPG concentration, there was no significant difference between Z-VEID- or Z-IETD-treated and control samples (Fig. 
$5 I)$. Together, these findings show that caspases 6 and 8 are involved in myelin but not in CSPG-mediated axonal outgrowth inhibition.

Caspase-6 inhibition promotes retinal ganglion cell survival in vivo

Optic nerve transection in adult rats induces the apoptotic death of $\sim 90 \%$ of RGCs by $14 \mathrm{~d}$ after axotomy (VillegasPérez et al., 1988; Berkelaar et al., 1994; Quigley et al., 1995). To determine whether caspase-6 is involved in RGC apoptosis after axotomy, we administered intraocular injections of selective caspase- 6 inhibitors and examined the effects on cell survival at $14 \mathrm{~d}$ after axotomy. Compared with normal retinas (Fig. 6A), RGC numbers declined substantially by $14 \mathrm{~d}$ after injury (Fig. $4 B$ ). At $14 \mathrm{~d}$, surviving RGCs were surrounded by transcellularly labeled microglia that had phagocytized dead RGCs and as a consequence had taken up the retrograde tracer. The average density of RGCs remaining in control saline-injected retinas was $370 \pm 25$ cells $/ \mathrm{mm}^{2}$. Intraocular delivery of Z-VEIDFMK, a selective inhibitor of caspase-6, significantly increased RGC survival at $14 \mathrm{~d}$ after axotomy (Fig. 6C,G) (1062 \pm 64 cells/ $\mathrm{mm}^{2}$ ). A small molecule inhibitor of caspase-6, SIMA 13a (Chu et al., 2009), similarly increased RGC survival twofold to threefold $\left(816 \pm 54\right.$ cells $\left./ \mathrm{mm}^{2}\right)$ relative to controls (Fig. 6D, G). We then compared the effects of caspase- 6 inhibition to caspase-9 or pancaspase inhibitors, Z-LEHDFMK or Z-VAD-FMK, respectively. These caspase inhibitors have previously been shown to promote RGC survival after axotomy (Kermer et al., 1998, 1999, 2000; Chaudhary et al., 1999; Weishaupt et al., 2003; Cheung et al., 2004). Both Z-LEHD and Z-VAD increased RGC survival by twofold to threefold (Fig. 6E-G), similar to caspase- 6 inhibition by SIMA 13a, however to a lesser extent than the caspase- 6 inhibitory peptide Z-VEID. Furthermore, in accordance with our in vitro data, caspase- 8 inhibition by Z-IETD had a similar effect on RGC survival to Z-VEID at $14 \mathrm{~d}$ after axotomy (Fig. 6G). Together, these results indicate that caspase- 6 plays an important role in the apoptotic death of axotomized RGCs.

Caspase- 6 or -8 inhibition promotes axonal regeneration after optic nerve crush

Myelin is a major impediment to axon regeneration in the adult mammalian CNS (Schwab, 1990; Nash et al., 2009; Nishio, 2009; Cao et al., 2010; Sun and He, 2010). We studied the effects of caspase- 6 and -8 inhibitors on the failure of axon regeneration by injured adult RGCs, using the well characterized optic nerve crush model (Misantone et al., 1984; Barron et al., 1986; Stevenson, 1987; Sautter and Sabel, 1993). This model is used to study axon regeneration by injured RGCs within the nonpermissive myelinated environment of the adult CNS. At 3 and $10 \mathrm{~d}$ follow-
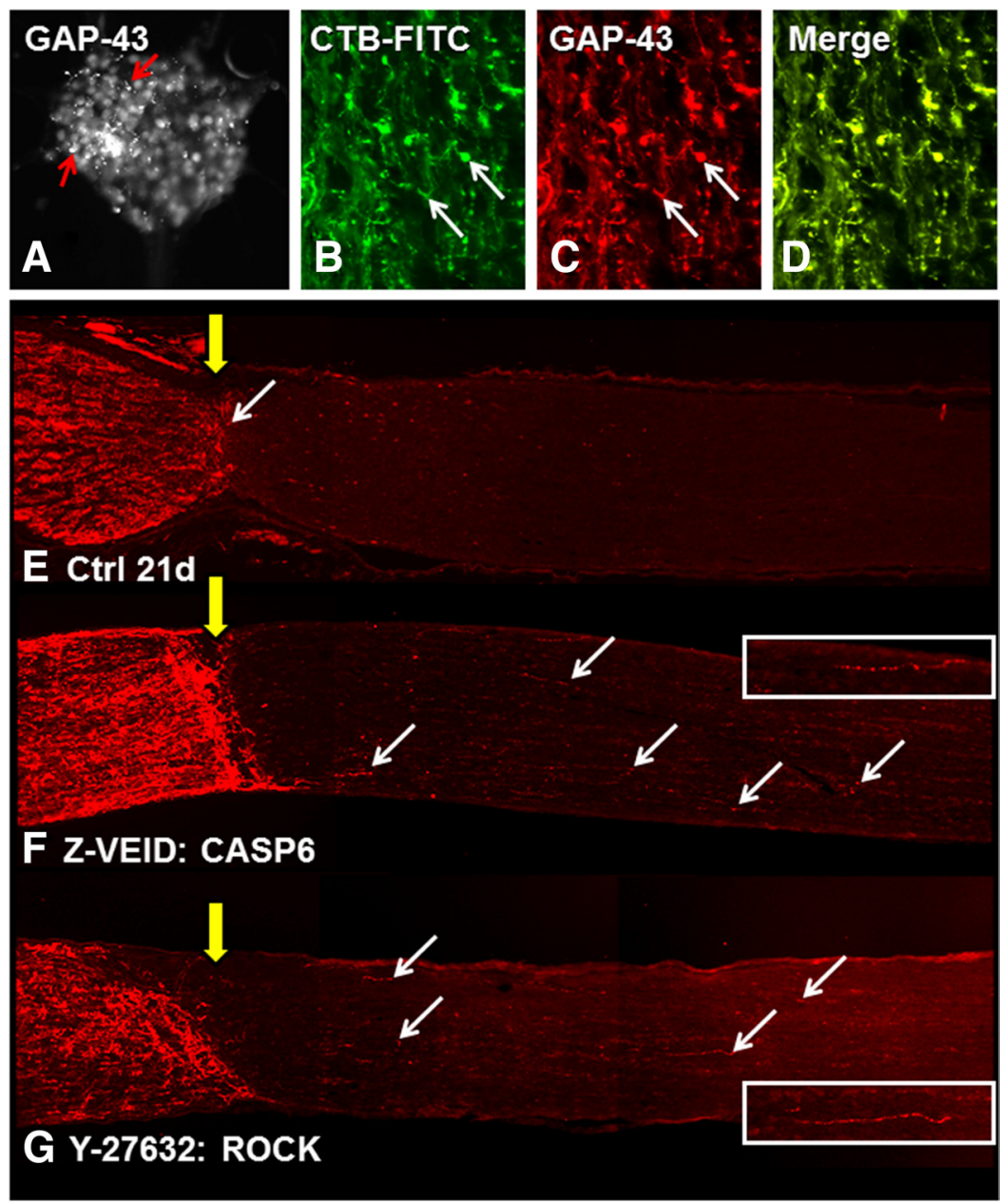

Figure 7. Caspase- 6 or ROCK inhibition promote axonal regeneration after optic nerve crush. A, GAP-43 immunostaining in cultured retinal precursor cells. $\boldsymbol{B}$, CTB-FITC was used to anterogradely label regenerating RGC axons after optic nerve crush. TB-FITC staining showed a 1:1 colabeling of regenerating RGC axons with GAP-43 (C; arrows) as demonstrated in a merge of the reatments. Compared with controls (E), CASP6 inhibition by Z-VEID-FMK $(\boldsymbol{F})$ enhanced axon regeneration past the crush site (ow arrow) and into the distal myelinated optic nerve. Similar regeneration was observed after ROCK inhibition by Y-27632 (G). of view. The retina (not visible) is toward the left side of the image. The inset images show higher magnification views of regenerating axons from the corresponding section.

ing optic nerve crush, animals received intraocular injections of caspase or ROCK inhibitors, and we examined axon regeneration through the crush site at $21 \mathrm{~d}$ after injury. Regenerating axons were visualized by GAP-43 immunostaining, since GAP-43 is a known constituent of axons in both the developing CNS and regenerating adult CNS neurons, including RGCs (Meyer et al., 1994; Berry et al., 1996; Leon et al., 2000; Su and Cho, 2003; Su et al., 2008, 2009). To verify GAP-43 labeling, we first stained cultures of retinal precursor cells at postnatal day 1. RGC cell bodies, axons, and growth cones, in spheres of retinal precursor cells, were positive for GAP-43 (Fig. 7A). Similarly, GAP-43 was localized to regenerating adult RGC axons of the proximal and distal nerve stump, as demonstrated by the colabeling of axons and growth cones with GAP-43 antisera and the anterograde tracer CTB-FITC (Fig. 7B-D), following intraocular injection of cholera toxin B. GAP-43 antisera colabeled all regenerating RGC axons that were CTB-FITC positive in our samples.

When the optic nerves of control and experimental animals were sectioned longitudinally, and immunohistochemistry for 

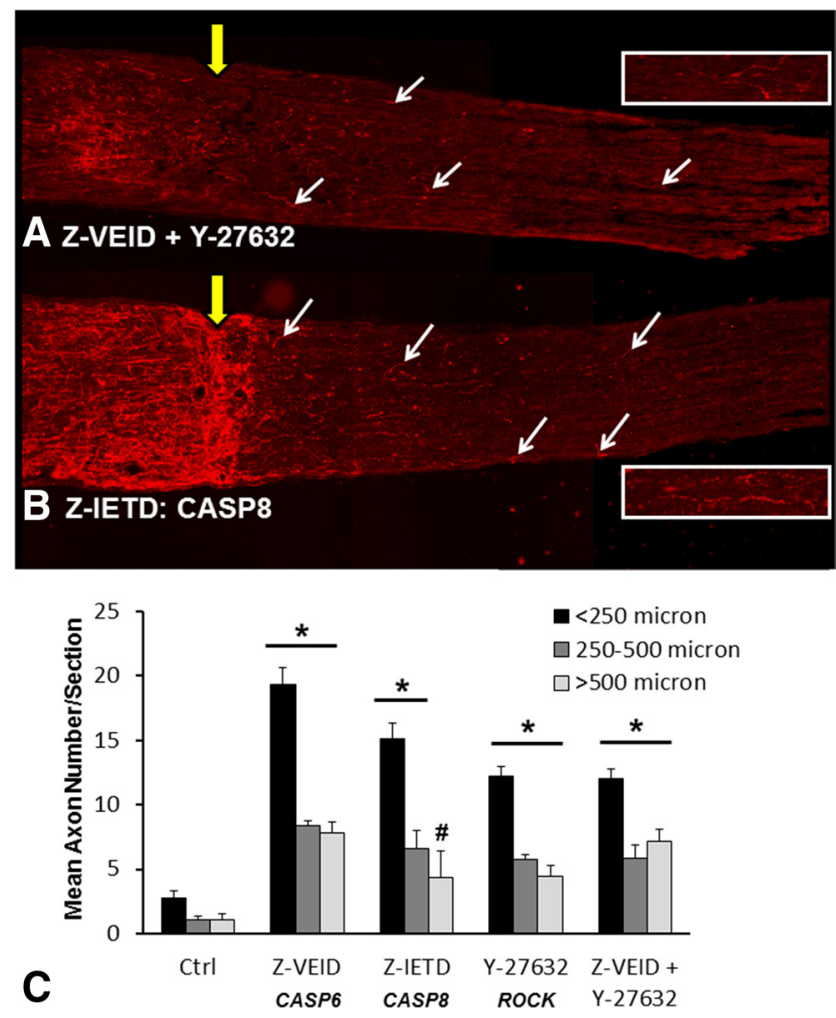

Figure 8. Caspase-8 inhibition increases axon regeneration after optic nerve crush. $\boldsymbol{A}, \boldsymbol{B}$, GAP-43 immunostaining in longitudinal sections of optic nerve at $21 \mathrm{~d}$ after optic nerve crush and combined inhibition of caspase-6 plus ROCK $(\boldsymbol{A})$, or caspase-8 inhibition ( $\boldsymbol{B}$; Z-IETD-FMK). Both treatments increased axon regeneration past the crush site (yellow arrow) and into the distal myelinated optic nerve. The arrows demarcate some of the regenerating axons in each nerve section. The retina (not visible) is toward the left side of the image. Each image is a composite of three successive fields of view. The inset images show higher magnification views of regenerating axons from the corresponding section. $C$, Quantification of the average number of regenerating axons per section ( \pm SEM) at different distances from the crush site. The number of axons was quantified in three different bins $(<250,250-500$, or $>500 \mu \mathrm{m})$. Intraocular injections of Z-VEID-FMK (caspase-6 inhibitor), Z-IETD-FMK (caspase-8 inhibitor), Y-27632 (ROCK inhibitor), or combined injection of Z-VEID-FMK plus Y-27632 significantly increased retinal ganglion cell regeneration following optic nerve crush. ${ }^{*} p<0.01$; ${ }^{\#} p<0.05$.

GAP-43 was performed, all nerves showed signs of extensive axonal sprouting and regeneration within the proximal nerve segment. In control treated animals, few axons were able to cross the lesion site within the myelinated optic nerve, and growth cones stopped abruptly at the crush site (Fig. 7E). The majority of regenerating axons in control animals were limited to $<250 \mu \mathrm{m}$ in length, and an average of approximately five regenerating axons per section were observed beyond the lesion site (Fig. $8 C)(<250$, $250-500$, and $>500 \mu \mathrm{m}: 3 \pm 0.5,1 \pm 0.27$, and $1 \pm 0.45)$. In contrast, animals treated with a caspase- 6 inhibitor (Z-VEIDFMK) showed robust axon regeneration beyond the lesion site (Fig. $7 F$ ), and more pronounced axon sprouting in the proximal segment of the nerve. Quantification of axon numbers by length demonstrated that caspase- 6 inhibition significantly increased the number of regenerating axons by approximately sevenfold to eightfold compared with controls (Fig. 8C) $(<250 \mu \mathrm{m}, 250-500$ $\mu \mathrm{m}$, and $>500 \mu \mathrm{m}: 19 \pm 0.5,8 \pm 0.37$, and $8 \pm 0.85)$. Some nerve sections from Z-VEID-treated animals had axons that extended $>1 \mathrm{~mm}$ beyond the lesion site, a feature that was never seen in controls at $21 \mathrm{~d}$ after crush. We then compared the effect of the ROCK inhibitor Y-27632, which has previously been shown to promote axonal regeneration after optic nerve lesion (Lingor et al., 2007, 2008; Ahmed et al., 2009). Animals that received Y-27632 showed robust axon regeneration beyond the lesion site, albeit to a lesser degree than caspase-6 inhibition (Figs. 7G, 8C). These findings show that caspase- 6 inhibition enhances axon regeneration in the myelinated adult CNS, with an efficacy equal to that of ROCK inhibition.

Since caspase- 6 is a direct activator of caspase-8 (Cowling and Downward, 2002; Inoue et al., 2009), we next examined whether caspase- 8 inhibition could promote axon regeneration after optic nerve crush. To test this possibility, animals were treated with Z-IETD to inhibit caspase-8. For all distances taken into consideration, the average number of axons per section was marginally less than in Z-VEID-treated animals; however, axon numbers were significantly higher than controls by approximately fivefold to sixfold $(<250,250-500$, and $>500 \mu \mathrm{m}: 15 \pm 1.2,7 \pm 1.4$, and $4 \pm 2$ ). To determine whether caspase- 6 inhibition and ROCK inhibition target different mechanisms for promoting axon regeneration, we administered combined injections of Z-VEID and Y-27632. Interestingly, this approach did not improve regeneration compared with individual delivery, suggesting that these treatments do not act independently of one another. Overall, these findings show that caspase- 6 and caspase- 8 play an important role in the failure of axon regeneration in the myelinated adult CNS.

\section{Caspase inhibition reduces retrograde axonal degeneration in vivo}

It has been demonstrated that retrograde Wallerian axonal degeneration in neurons is dependent on caspase-6 (Nikolaev et al., 2009), and our findings show that caspase- 6 participates in both neuronal apoptosis and the failure of axon regeneration in the adult CNS. Therefore, we also examined the intraretinal integrity of RGC axons after optic nerve crush to look for signs of increased axon preservation by caspase- 6 or -8 inhibitors. Animals received intraocular injections of CTB-FITC, an anterograde tracer that is useful for assaying active protein transport in the axons of neurons. The retinas were flat-mounted $2 \mathrm{~d}$ later (at $21 \mathrm{~d}$ after crush), and we examined the integrity of RGC axons in the nerve fiber layer, in the inner, midperiphery, and outer retina (Fig. 9). In control animals, axon bundles appeared thin in the central part of the retina, near the optic disc, where RGC axons exit the eye (Fig. $9 A$ ), and only a few projections could be observed in the midperiphery (Fig. 9B) and outer retina (Fig. 9C). The cell bodies of surviving RGCs with intact axons were also visibly labeled with CTB-FITC (Fig. 9A-C). Treatment with Z-VEID (Fig. 9D-F) or Z-IETD (Fig. 9G-I) resulted in (1) thicker axon bundles throughout the retina and (2) increased labeling of RGC somata, which is consistent with a role of these caspases in both cell survival and axonal regeneration. Similar results were observed after ROCK inhibition (Fig. 9J-L), and no additional improvement was seen after combined inhibition of caspase- 6 and ROCK (Fig. $9 M-O)$. Overall, our findings suggest that both caspase- 6 and caspase- 8 play a role in loss of intraretinal axon integrity after optic nerve transection.

\section{Discussion}

The data presented here demonstrate novel functions for caspase- 6 and -8 after adult CNS insult. We showed that caspase- 6 is activated after optic nerve injury, and caspase- 6 inhibition promotes RGC survival both in vitro and in vivo. We also show that caspase- 6 inhibition promotes axonal outgrowth on myelin, but not on CSPGs, and induces axonal regeneration in vivo. Moreover, we demonstrated that caspase- 8 is activated 
downstream of caspase-6 in injured RGCs. Consistent with this finding, caspase- 8 inhibition also enhanced RGC survival and regeneration. Overall, these findings demonstrate a prominent role for caspase- 6 and caspase- 8 in adult CNS neuron apoptosis and regenerative failure within myelinated CNS tissue.

The role of caspases in RGC survival Retinal caspase- $3,-8$, and -9 activity have been shown to play an important role in RGC apoptosis following optic nerve transection (Kermer et al., 1998, 1999, 2000; Chaudhary et al., 1999; Weishaupt et al., 2003; Cheung et al., 2004). Our study demonstrates that caspase- 6 is localized to RGC cell bodies in the ganglion cell layer, suggestive of a role in cell death after axotomy. In vitro, the addition of the caspase- 6 inhibitor Z-VEID to the medium had a strong neuroprotective effect. This was replicated in vivo after intraocular injection of the two caspase- 6 inhibitors following optic nerve transection, establishing caspase- 6 as a central executioner in RGC apoptosis after axotomy.

There is accumulating evidence that cell death receptors can trigger apoptosis in injured neurons. For instance, Fas ligand binding to its death receptor induces apoptosis through the activation of caspase-8, followed by caspase-3, and -9 (Muzio et al., 1998; Weishaupt et al., 2003; Kim and Park, 2005). Similarly, caspase- 6 can be activated by death receptor-6 (Nikolaev et al., 2009). Despite these findings, it is unclear how caspase- 8 is activated in injured adult RGCs, since death receptor ligands do not increase caspase- 8 cleavage after intraocular delivery (Weishaupt et al., 2003). Interestingly, caspase- 6 is a direct activator of caspase- 8 (Cowling and Downward, 2002; Inoue et al., 2009). We show that caspase- 6 inhibition results in a pronounced reduction in caspase- 8 activation. In contrast, caspase- 8 inhibition produced a small reduction in caspase- 6 activation, suggesting that the effects we observed are not solely dependent on recurrent caspase-6/8 activation. Additional evidence supports this contention: Our in vitro assays showed a dramatic effect of caspase- 8 inhibition at 1 or $4 \mathrm{~d}$ after explant and caspase activation is apparent at 3-4 d after axotomy (Bähr, 2000; Koeberle and Bähr, 2004), whereas caspase- 6 activation at this time point was not affected by caspase- 8 inhibition. Furthermore, caspase- 6 activation remains well beyond the levels necessary to promote apoptosis in the presence of caspase- 8 inhibitors (Yang et al., 2008). Overall, caspase- 8 appears to be an important mediator of caspase-6-dependent RGC apoptosis.

\section{Role of caspases in regenerating axons}

Early attempts to characterize factors that control axon degeneration showed that caspase inhibitors did not prevent axon degeneration (Kuida et al., 1996; Finn et al., 2000). In accordance, it was postulated that axonal degeneration was caspase independent. The recent findings that this process is orchestrated by caspase- 6 contradict this notion (Nikolaev et al., 2009; Park et al., 2010). These studies prompted us to test the hypothesis that caspase- 6 is involved in the failure of adult CNS regeneration after injury. Our study shows that caspase- 6 is expressed in injured retinal ganglion cells and axons in the nerve fiber layer, and that its inhibition promotes regeneration after optic nerve injury. In vitro data demonstrated that caspase-6/8 are involved in the intracellular pathway that mediates myelin inhibition in regenerating RGC growth cones. Thus, to our knowledge, this article provides the first evidence for a role of caspases in the failure of neuronal regeneration in the injured adult CNS. 
Caspase-6 degrades mainly nuclear and cytoskeletal components. These include nuclear laminins, NUMA (nuclear mitotic apparatus protein) SATB1 (special AT-rich binding protein-1) (Inoue et al., 2009). In neurons, CASP6 can also trigger the destabilization of microtubules (Guo et al., 2004; Nikolaev et al., 2009), via cleavage of microtubule-associated proteins such as TAU (Nikolaev et al., 2009). Furthermore, proteomic analysis has demonstrated that $\sim 40 \%$ of caspase- 6 substrates are cytoskeletal components and cytoskeleton-associated proteins (Klaiman et al., 2008). In accordance, the degradation of cytoskeletal elements by caspase- 6 may contribute to the failure of RGC axon regeneration. Another possible mechanism is the activation of caspase-8.

Caspase- 8 also acts on targets that regulate cytoskeletal dynamics. An important substrate of caspase- 8 is the $\mathrm{p} 21$-activated kinase (PAK) family of serine/threonine kinases (Fischer et al., 2006). PAKs, together with Rho family GTPase members Cdc42 and Rac, are critical in cytoskeletal organization and dynamics that play a role in cell movement, migration, adhesion, and neurite outgrowth (Shin et al., 2002, 2004, 2009; Thies and Davenport, 2003; Chen et al., 2006; Quinn and Wadsworth, 2008; Szczepanowska, 2009; Tahirovic et al., 2010). Interactions between Rac, Cdc42, and PAKs control the formation of filopodia, membrane ruffles, and focal adhesion remodeling through the modulation of targets such as Cdk5, Raf, Tubulin cofactor B, Rho-GEFs, and Filamin (Szczepanowska, 2009). PAK2 is one of the primary substrates of caspase- 8 (Fischer et al., 2006), and the maintenance of PAK2 function may be critical for promoting axon regeneration by adult RGCs.

Caspase- 8 has also been shown to cleave and activate ROCK, independently of caspase-3 (Ehrenschwender et al., 2010). Since ROCK is a well known inhibitor of axon regeneration by adult RGCs (Monnier et al., 2003; Lingor et al., 2007, 2008; Ahmed et al., 2009), caspase- 8 likely contributes to the failure of axon regeneration through modulating ROCK activity.

\section{Regeneration and degeneration: two different cellular processes, one molecular mechanism?}

Neuronal degeneration and regeneration are two distinct events; one leads to the destruction of axons, whereas the other induces their creation. Axonal degeneration is characterized by $\beta I I I-$ tubulin fragmentation, which causes axonal retraction (Park et al., 2010), whereas regeneration is characterized by increased $\beta$ III-tubulin polymerization (Lund et al., 2002). Thus, at the cellular level, both events appear to be opposite in nature. The molecular mechanisms that regulate degeneration and regeneration are still under investigation. Myelin is a major inhibitor of axonal regeneration in the adult brain (Schwab, 1990; Wang et al., 2002; Fournier et al., 2003). It contains several growth-inhibitory proteins (e.g., Nogo, MAG, OMgp) that interact with the Nogo and the p75 receptors to stop axonal extension (Wang et al., 2002). There is also evidence that myelin promotes axonal degeneration via p75 activation (Park et al., 2010). In both cases, p75 activates the Rho-ROCK pathway (Wang et al., 2002; Park et al., 2010) and involves caspase-6 (Nikolaev et al., 2009; Park et al., 2010). In addition, our data show that caspase- 6 hampers adult neuron regeneration in the mammalian CNS. Thus, axonal regeneration and degeneration appear to be controlled, at least in part, through a p75-Rho-ROCK-caspase-6 mechanism. In the case of axonal regeneration, our study adds caspase- 8 to this panel of intracellular effectors and it will be interesting to see whether caspase- 8 acts downstream of caspase- 6 in Wallerian degeneration.

\section{Role of caspase- 6 and caspase- 8 in CNS neuropathology}

There are multiple experimental links between caspase- 6 and diseases of the adult CNS, including Alzheimer's disease (LeBlanc et al., 1999; Mattson, 2006; Baumgartner et al., 2009; Nikolaev et al., 2009). $\beta$-Amyloid triggers the degeneration of axons via caspase- 6 (LeBlanc et al., 1999; Nikolaev et al., 2009). Furthermore, caspase-6 activation has been detected in postmortem Alzheimer brain issue (Baumgartner et al., 2009). Another neurodegenerative disease that involves caspase-6 is Huntington's disease (Graham et al., 2006; Baumgartner et al., 2009). One of the hallmarks of Huntington's disease is the accumulation of N-terminal Huntingtin (htt) protein fragments in the brain, a consequence of caspase-6-mediated cleavage of mutant htt at amino acid 586 (Graham et al., 2006).

Similar to caspase- 6 , active caspase- 8 has been localized throughout the brains of Alzheimer's patients and has been shown to mediate neuronal apoptosis induced by $\beta$-amyloid treatment or Presenilin-1 mutations (Ivins et al., 1999; Rohn et al., 2001; Yew et al., 2004; Matsui et al., 2006; Miyoshi et al., 2009; Vaisid et al., 2009). Caspase-8 is further implicated in Parkinson's disease. Elevated caspase- 8 levels were observed in human postmortem brain (Hartmann et al., 2001), and in the MPTP model of Parkinson's disease (Hartmann et al., 2001; Viswanath et al., 2001). Furthermore, caspase- 8 is critical for apoptosis induced by Parkinson-associated mutations in leucine-rich repeat kinase 2 (Ho et al., 2009).

The present data may also be relevant to visual diseases whose hallmark is retinal ganglion cell degeneration. RGC apoptosis is observed in diseases that include glaucoma, traumatic and hereditary optic neuropathy, and diabetic retinopathy (Cheung et al., 2010; Milea et al., 2010; Qu et al., 2010; Warner and Eggenberger, 2010).

Our findings demonstrate a prominent role for caspases 6 and 8 in the apoptotic cell death and regenerative failure of injured adult retinal ganglion cells. These findings suggest that targeting caspase- 6 and -8 has potential therapeutic value for adult CNS trauma and diseases of the CNS that feature caspase- 6 activation.

\section{References}

Ahmed Z, Berry M, Logan A (2009) ROCK inhibition promotes adult retinal ganglion cell neurite outgrowth only in the presence of growth promoting factors. Mol Cell Neurosci 42:128-133.

Bähr M (2000) Live or let die—retinal ganglion cell death and survival during development and in the lesioned adult CNS. Trends Neurosci 23:483-490.

Barron KD, Dentinger MP, Krohel G, Easton SK, Mankes R (1986) Qualitative and quantitative ultrastructural observations on retinal ganglion cell layer of rat after intraorbital optic nerve crush. J Neurocytol 15:345-362.

Baumgartner R, Meder G, Briand C, Decock A, D’arcy A, Hassiepen U, Morse $R$, Renatus M (2009) The crystal structure of caspase- 6 , a selective effector of axonal degeneration. Biochem J 423:429-439.

Berkelaar M, Clarke DB, Wang YC, Bray GM, Aguayo AJ (1994) Axotomy results in delayed death and apoptosis of retinal ganglion cells in adult rats. J Neurosci 14:4368-4374.

Berry M, Carlile J, Hunter A (1996) Peripheral nerve explants grafted into the vitreous body of the eye promote the regeneration of retinal ganglion cell axons severed in the optic nerve. J Neurocytol 25:147-170.

Cao Z, Gao Y, Deng K, Williams G, Doherty P, Walsh FS (2010) Receptors for myelin inhibitors: structures and therapeutic opportunities. Mol Cell Neurosci 43:1-14.

Chaudhary P, Ahmed F, Quebada P, Sharma SC (1999) Caspase inhibitors block the retinal ganglion cell death following optic nerve transection. Brain Res Mol Brain Res 67:36-45.

Chen C, Chen X, Yin X, Yuan R, Wang B, Ye J (2009) NgR RNA interference, combined with zymosan intravitreal injection, enhances optic nerve regeneration. J Neurochem 110:1628-1634.

Chen TJ, Gehler S, Shaw AE, Bamburg JR, Letourneau PC (2006) Cdc42 
participates in the regulation of $\mathrm{ADF} /$ cofilin and retinal growth cone filopodia by brain-derived neurotrophic factor. J Neurobiol 66:103-114.

Cheung N, Mitchell P, Wong TY (2010) Diabetic retinopathy. Lancet 376:124-136

Cheung ZH, Chan YM, Siu FK, Yip HK, Wu W, Leung MC, So KF (2004) Regulation of caspase activation in axotomized retinal ganglion cells. Mol Cell Neurosci 25:383-393.

Chu W, Rothfuss J, Chu Y, Zhou D, Mach RH (2009) Synthesis and in vitro evaluation of sulfonamide isatin Michael acceptors as small molecule inhibitors of caspase-6. J Med Chem 52:2188-2191.

Cowling V, Downward J (2002) Caspase-6 is the direct activator of caspase- 8 in the cytochrome $c$-induced apoptosis pathway: absolute requirement for removal of caspase- 6 prodomain. Cell Death Differ 9:1046-1056.

Cui Q, Cho KS, So KF, Yip HK (2004) Synergistic effect of Nogoneutralizing antibody IN-1 and ciliary neurotrophic factor on axonal regeneration in adult rodent visual systems. J Neurotrauma 21:617-625.

DeBellard ME, Tang S, Mukhopadhyay G, Shen YJ, Filbin MT (1996) Myelin-associated glycoprotein inhibits axonal regeneration from a variety of neurons via interaction with a sialoglycoprotein. Mol Cell Neurosci 7:89-101.

Degterev A, Boyce M, Yuan J (2003) A decade of caspases. Oncogene 22:8543-8567.

Ehrenschwender M, Siegmund D, Wicovsky A, Kracht M, Dittrich-Breiholz O, Spindler V, Waschke J, Kalthoff H, Trauzold A, Wajant H (2010) Mutant PIK3CA licenses TRAIL and CD95L to induce non-apoptotic caspase-8-mediated ROCK activation. Cell Death Differ 17:1435-1447.

Finn JT, Weil M, Archer F, Siman R, Srinivasan A, Raff MC (2000) Evidence that Wallerian degeneration and localized axon degeneration induced by local neurotrophin deprivation do not involve caspases. J Neurosci 20:1333-1341.

Fischer D, He Z, Benowitz LI (2004) Counteracting the Nogo receptor enhances optic nerve regeneration if retinal ganglion cells are in an active growth state. J Neurosci 24:1646-1651.

Fischer U, Stroh C, Schulze-Osthoff K (2006) Unique and overlapping substrate specificities of caspase-8 and caspase-10. Oncogene 25:152-159.

Fournier AE, Gould GC, Liu BP, Strittmatter SM (2002) Truncated soluble Nogo receptor binds Nogo-66 and blocks inhibition of axon growth by myelin. J Neurosci 22:8876-8883.

Fournier AE, Takizawa BT, Strittmatter SM (2003) Rho kinase inhibition enhances axonal regeneration in the injured CNS. J Neurosci 23:1416-1423.

Graham RK, Deng Y, Slow EJ, Haigh B, Bissada N, Lu G, Pearson J, Shehadeh J, Bertram L, Murphy Z, Warby SC, Doty CN, Roy S, Wellington CL, Leavitt BR, Raymond LA, Nicholson DW, Hayden MR (2006) Cleavage at the caspase- 6 site is required for neuronal dysfunction and degeneration due to mutant huntingtin. Cell 125:1179-1191.

Guo H, Albrecht S, Bourdeau M, Petzke T, Bergeron C, LeBlanc AC (2004) Active caspase- 6 and caspase-6-cleaved tau in neuropil threads, neuritic plaques, and neurofibrillary tangles of Alzheimer's disease. Am J Pathol 165:523-531.

Hartmann A, Troadec JD, Hunot S, Kikly K, Faucheux BA, Mouatt-Prigent A, Ruberg M, Agid Y, Hirsch EC (2001) Caspase-8 is an effector in apoptotic death of dopaminergic neurons in Parkinson's disease, but pathway inhibition results in neuronal necrosis. J Neurosci 21:2247-2255.

Ho CC, Rideout HJ, Ribe E, Troy CM, Dauer WT (2009) The Parkinson disease protein leucine-rich repeat kinase 2 transduces death signals via Fas-associated protein with death domain and caspase- 8 in a cellular model of neurodegeneration. J Neurosci 29:1011-1016.

Horner PJ, Gage FH (2000) Regenerating the damaged central nervous system. Nature 407:963-970.

Inoue S, Browne G, Melino G, Cohen GM (2009) Ordering of caspases in cells undergoing apoptosis by the intrinsic pathway. Cell Death Differ 16:1053-1061.

Ivins KJ, Thornton PL, Rohn TT, Cotman CW (1999) Neuronal apoptosis induced by beta-amyloid is mediated by caspase- 8 . Neurobiol Dis 6:440-449.

Kermer P, Klöcker N, Labes M, Bähr M (1998) Inhibition of CPP32-like proteases rescues axotomized retinal ganglion cells from secondary cell death in vivo. J Neurosci 18:4656-4662.

Kermer P, Klöcker N, Bähr M (1999) Long-term effect of inhibition of ced 3-like caspases on the survival of axotomized retinal ganglion cells in vivo. Exp Neurol 158:202-205.

Kermer P, Ankerhold R, Klöcker N, Krajewski S, Reed JC, Bähr M (2000) Caspase-9: involvement in secondary death of axotomized rat retinal ganglion cells in vivo. Brain Res Mol Brain Res 85:144-150.

Kim HS, Park CK (2005) Retinal ganglion cell death is delayed by activation of retinal intrinsic cell survival program. Brain Res 1057:17-28.

Klaiman G, Petzke TL, Hammond J, Leblanc AC (2008) Targets of caspase-6 activity in human neurons and Alzheimer disease. Mol Cell Proteomics 7:1541-1555.

Koeberle PD, Bähr M (2004) Growth and guidance cues for regenerating axons: where have they gone? J Neurobiol 59:162-180.

Koeberle PD, Bähr M (2008) The upregulation of GLAST-1 is an indirect antiapoptotic mechanism of GDNF and neurturin in the adult CNS. Cell Death Differ 15:471-483.

Koeberle PD, Tura A, Tassew NG, Schlichter LC, Monnier PP (2010) The repulsive guidance molecule, RGMa, promotes retinal ganglion cell survival in vitro and in vivo. Neuroscience 169:495-504.

Kuida K, Zheng TS, Na S, Kuan C, Yang D, Karasuyama H, Rakic P, Flavell RA (1996) Decreased apoptosis in the brain and premature lethality in CPP32-deficient mice. Nature 384:368-372.

LeBlanc A, Liu H, Goodyer C, Bergeron C, Hammond J (1999) Caspase-6 role in apoptosis of human neurons, amyloidogenesis, and Alzheimer's disease. J Biol Chem 274:23426-23436.

Leon S, Yin Y, Nguyen J, Irwin N, Benowitz LI (2000) Lens injury stimulates axon regeneration in the mature rat optic nerve. J Neurosci 20:4615-4626.

Li M, Shibata A, Li C, Braun PE, McKerracher L, Roder J, Kater SB, David S (1996) Myelin-associated glycoprotein inhibits neurite/axon growth and causes growth cone collapse. J Neurosci Res 46:404-414.

Lingor P, Teusch N, Schwarz K, Mueller R, Mack H, Bähr M, Mueller BK (2007) Inhibition of Rho kinase (ROCK) increases neurite outgrowth on chondroitin sulphate proteoglycan in vitro and axonal regeneration in the adult optic nerve in vivo. J Neurochem 103:181-189.

Lingor P, Tönges L, Pieper N, Bermel C, Barski E, Planchamp V, Bähr M (2008) ROCK inhibition and CNTF interact on intrinsic signalling pathways and differentially regulate survival and regeneration in retinal ganglion cells. Brain 131:250-263.

Lund LM, Machado VM, McQuarrie IG (2002) Increased beta-actin and tubulin polymerization in regrowing axons: relationship to the conditioning lesion effect. Exp Neurol 178:306-312.

Matsui T, Ramasamy K, Ingelsson M, Fukumoto H, Conrad C, Frosch MP, Irizarry MC, Yuan J, Hyman BT (2006) Coordinated expression of caspase 8, 3 and 7 mRNA in temporal cortex of Alzheimer disease: relationship to formic acid extractable A $\beta 42$ levels. J Neuropathol Exp Neurol 65:508-515.

Mattson MP (2006) Neuronal life-and-death signaling, apoptosis, and neurodegenerative disorders. Antioxid Redox Signal 8:1997-2006.

McKerracher L, David S, Jackson DL, Kottis V, Dunn RJ, Braun PE (1994) Identification of myelin-associated glycoprotein as a major myelinderived inhibitor of neurite growth. Neuron 13:805-811.

Meyer RL, Miotke JA, Benowitz LI (1994) Injury induced expression of growth-associated protein- 43 in adult mouse retinal ganglion cells in vitro. Neuroscience 63:591-602.

Milea D, Amati-Bonneau P, Reynier P, Bonneau D (2010) Genetically determined optic neuropathies. Curr Opin Neurol 23:24-28.

Misantone LJ, Gershenbaum M, Murray M (1984) Viability of retinal ganglion cells after optic nerve crush in adult rats. J Neurocytol 13:449-465.

Miyoshi K, Ohyagi Y, Sakae N, Motomura K, Ma L, Taniwaki T, Furuya H, Tabira T, Kira J (2009) Enhancement of activation of caspases by presenilin 1 gene mutations and its inhibition by secretase inhibitors. J Alzheimers Dis 16:551-564.

Monnier PP, Sierra A, Schwab JM, Henke-Fahle S, Mueller BK (2003) The Rho/ROCK pathway mediates neurite growth-inhibitory activity associated with the chondroitin sulfate proteoglycans of the CNS glial scar. Mol Cell Neurosci 22:319-330.

Muzio M, Stockwell BR, Stennicke HR, Salvesen GS, Dixit VM (1998) An induced proximity model for caspase-8 activation. J Biol Chem 273:2926-2930.

Nash M, Pribiag H, Fournier AE, Jacobson C (2009) Central nervous system regeneration inhibitors and their intracellular substrates. Mol Neurobiol 40:224-235. 
Nikolaev A, McLaughlin T, O’Leary DD, Tessier-Lavigne M (2009) APP binds DR6 to trigger axon pruning and neuron death via distinct caspases. Nature 457:981-989.

Nishio T (2009) Axonal regeneration and neural network reconstruction in mammalian CNS. J Neurol 256 [Suppl 3]:306-309.

Park KJ, Grosso CA, Aubert I, Kaplan DR, Miller FD (2010) p75NTRdependent, myelin-mediated axonal degeneration regulates neural connectivity in the adult brain. Nat Neurosci 13:559-566.

Qu J, Wang D, Grosskreutz CL (2010) Mechanisms of retinal ganglion cell injury and defense in glaucoma. Exp Eye Res 91:48-53.

Quigley HA, Nickells RW, Kerrigan LA, Pease ME, Thibault DJ, Zack DJ (1995) Retinal ganglion cell death in experimental glaucoma and after axotomy occurs by apoptosis. Invest Ophthalmol Vis Sci 36:774-786.

Quinn CC, Wadsworth WG (2008) Axon guidance: asymmetric signaling orients polarized outgrowth. Trends Cell Biol 18:597-603.

Rohn TT, Head E, Nesse WH, Cotman CW, Cribbs DH (2001) Activation of caspase-8 in the Alzheimer's disease brain. Neurobiol Dis 8:1006-1016.

Sautter J, Sabel BA (1993) Recovery of brightness discrimination in adult rats despite progressive loss of retrogradely labelled retinal ganglion cells after controlled optic nerve crush. Eur J Neurosci 5:680-690.

Schwab ME (1990) Myelin-associated inhibitors of neurite growth and regeneration in the CNS. Trends Neurosci 13:452-456.

Shin EY, Shin KS, Lee CS, Woo KN, Quan SH, Soung NK, Kim YG, Cha CI, Kim SR, Park D, Bokoch GM, Kim EG (2002) Phosphorylation of p85 beta PIX, a Rac/Cdc42-specific guanine nucleotide exchange factor, via the Ras/ERK/PAK2 pathway is required for basic fibroblast growth factorinduced neurite outgrowth. J Biol Chem 277:44417-44430.

Shin EY, Woo KN, Lee CS, Koo SH, Kim YG, Kim WJ, Bae CD, Chang SI, Kim EG (2004) Basic fibroblast growth factor stimulates activation of Rac1 through a 85 betaPIX phosphorylation-dependent pathway. J Biol Chem 279:1994-2004.

Shin EY, Shim ES, Lee CS, Kim HK, Kim EG (2009) Phosphorylation of RhoGDI1 by p21-activated kinase 2 mediates basic fibroblast growth factor-stimulated neurite outgrowth in PC12 cells. Biochem Biophys Res Commun 379:384-389.

Stevenson JA (1987) Growth of retinal ganglion cell axons following optic nerve crush in adult hamsters. Exp Neurol 97:77-89.

Su HX, Cho EY (2003) Sprouting of axon-like processes from axotomized retinal ganglion cells induced by normal and preinjured intravitreal optic nerve grafts. Brain Res 991:150-162.

Su Y, Wang F, Zhao SG, Pan SH, Liu P, Teng Y, Cui H (2008) Axonal regeneration after optic nerve crush in Nogo-A/B/C knockout mice. Mol Vis 14:268-273.
Su Y, Wang F, Teng Y, Zhao SG, Cui H, Pan SH (2009) Axonal regeneration of optic nerve after crush in Nogo66 receptor knockout mice. Neurosci Lett 460:223-226.

Sun F, He Z (2010) Neuronal intrinsic barriers for axon regeneration in the adult CNS. Curr Opin Neurobiol 20:510-518.

Szczepanowska J (2009) Involvement of Rac/Cdc42/PAK pathway in cytoskeletal rearrangements. Acta Biochim Pol 56:225-234.

Tahirovic S, Hellal F, Neukirchen D, Hindges R, Garvalov BK, Flynn KC, Stradal TE, Chrostek-Grashoff A, Brakebusch C, Bradke F (2010) Racl regulates neuronal polarization through the WAVE complex. J Neurosci 30:6930-6943.

Thies E, Davenport RW (2003) Independent roles of Rho-GTPases in growth cone and axonal behavior. J Neurobiol 54:358-369.

Vaisid T, Barnoy S, Kosower NS (2009) Calpain activates caspase-8 in neuron-like differentiated PC12 cells via the amyloid-beta-peptide and CD95 pathways. Int J Biochem Cell Biol 41:2450-2458.

Villegas-Pérez MP, Vidal-Sanz M, Bray GM, Aguayo AJ (1988) Influences of peripheral nerve grafts on the survival and regrowth of axotomized retinal ganglion cells in adult rats. J Neurosci 8:265-280.

Viswanath V, Wu Y, Boonplueang R, Chen S, Stevenson FF, Yantiri F, Yang L, Beal MF, Andersen JK (2001) Caspase-9 activation results in downstream caspase- 8 activation and bid cleavage in 1-methyl-4-phenyl1,2,3,6-tetrahydropyridine-induced Parkinson's disease. J Neurosci 21:9519-9528.

Wang KC, Kim JA, Sivasankaran R, Segal R, He Z (2002) p75 interacts with the Nogo receptor as a co-receptor for Nogo, MAG and OMgp. Nature 420:74-78

Warner N, Eggenberger E (2010) Traumatic optic neuropathy: a review of the current literature. Curr Opin Ophthalmol 21:459-462.

Weishaupt JH, Diem R, Kermer P, Krajewski S, Reed JC, Bähr M (2003) Contribution of caspase- 8 to apoptosis of axotomized rat retinal ganglion cells in vivo. Neurobiol Dis 13:124-135.

Wong EV, David S, Jacob MH, Jay DG (2003) Inactivation of myelinassociated glycoprotein enhances optic nerve regeneration. J Neurosci 23:3112-3117.

Yang C, Kaushal V, Haun RS, Seth R, Shah SV, Kaushal GP (2008) Transcriptional activation of caspase- 6 and -7 genes by cisplatin-induced p53 and its functional significance in cisplatin nephrotoxicity. Cell Death Differ 15:530-544.

Yew DT, Ping Li W, Liu WK (2004) Fas and activated caspase 8 in normal, Alzheimer and multiple infarct brains. Neurosci Lett 367:113-117.

Yi CH, Yuan J (2009) The Jekyll and Hyde functions of caspases. Dev Cell $16: 21-34$. 